\title{
FICHTE E 0 SABER ABSOLUTO NA DOUTRINA-DA-CIÊNCIA DE 1804
}

\author{
Thiago S. Santoro \\ PPGFIL - PUCRS
}

\begin{abstract}
The second lecture series on the Wissenschaftslehre (WL) of 1804 intends to establish a new theoretical frame for Fichte's philosophical project. One of the main goals of this text is to present what would be the possible epistemic relation between the knowing subject and the presupposition of the absolute, which always surpasses any conceptual knowledge. In this paper, I try to reconstruct Fichte's arguments regarding the first part of WL 1804, known as 'Aufstieg' of the WL.
\end{abstract}

Keywords: Fichte, absolute knowledge, German Idealism.

Resumo: A segunda séria de preleções sobre a Doutrina-da-Ciência (WL) de 1804 pretende estabelecer um novo marco teórico no projeto filosófico de Fichte. Um dos principais objetivos do texto é mostrar qual a possível relação epistêmica entre o sujeito cognitivo e a pressuposição do absoluto, que sempre ultrapassa qualquer saber conceitual. Nesse artigo, faço uma breve reconstrução dos argumentos de Fichte referentes à primeira parte do texto de 1804, conhecida como 'via ascendente' da Doutrina-da-Ciência.

Palavras-chave: Fichte, saber absoluto, Idealismo Alemão.

Para o homem individual também existem verdades viventes e verdades mortas. Encontra-se morta a verdade verificada, consagrada pelo outro e na qual já não se entra, a que já não se pode voltar a verificar circularmente. A verdade se converte então em um em-si (posto que foi fixada como em-si pelo outro).

Sartre, J-P. Vérité et Existence

Duas são as formas de compreender o pensamento humano. Nossa atividade mental reflexiva, que sempre postula um objeto diante de si e ao mesmo tempo se objetifica na sua contraposição ao mesmo objeto, pode ser 
analisada a partir de ambos os lados da relação. Se adotamos o ponto de vista do sujeito conhecedor, a filosofia torna-se idealismo; se adotamos o ponto de vista da objetividade do mundo, chegamos ao realismo filosófico. Tal divisão, de acordo com Fichte, permeia toda a história da filosofia, cujo primeiro ponto de corte encontra-se verdadeiramente no transcendentalismo de Kant.

Mas a primeira Crítica kantiana não legou apenas sua reviravolta copernicana, encontrando na estrutura subjetiva as condições de possibilidade de toda experiência - ela também instaurou no espírito de sua época a idéia de filosofia como sistema. Assim, é na combinação destas duas epígrafes de Kant que surge o elemento motivador determinante do idealismo alemão subseqüente. A bem dizer, não se trata aqui de simples combinatória, mas sim do conflito que a conjunção de tais inovações filosóficas acarreta. Podemos dizer que grande parte do desenvolvimento filosófico pós-kantiano pretendeu responder à seguinte dificuldade: como é possível reunificar mundo e razão a partir de um mesmo princípio? Em outras palavras, como é possível conservar a conquista da dimensão transcendental, que determina uma forma a priori de conhecimento racional legítimo do mundo, e ao mesmo tempo recuperar a unidade sistemática que a tudo subjaz, a identidade absoluta que deve sintetizar qualquer duplicidade ou dualismo?

Fichte pretendeu responder a esta dificuldade radicalizando o projeto kantiano, repensando toda forma sistemática de explicação do mundo objetivo a partir da própria estrutura transcendental. Mas foi justamente uma má compreensão desta proposta fichtiana aquilo que durante muito destinou para sua filosofia a alcunha de um idealismo meramente subjetivo. $O$ que deveria ser uma continuação coerente do sistema de filosofia transcendental, desenvolvido a partir do princípio da subjetividade transcendental postulado por Kant na primeira Crítica, transformou-se para os leitores da época em uma egolatria desmedida articulada em termos os mais obscuros.

Entretanto, a obra de Fichte não se resume a uma simples afirmação do eu. Tampouco podemos dizer que Fichte simplesmente adota o ponto de vista de um idealismo restrito, quase ingênuo, que deduz toda realidade efetiva a partir de meros conceitos, tirando um leão, como diz Santo Agostinho, da boca de quem o pronuncia. O projeto fichtiano de um idealrealismo busca superar a dicotomia entre razão e experiência, investigando no próprio processo de autoconstrução do saber a origem ou gênese da duplicidade entre ser e conceito, ou seja, entre o mundo obscuro do em-si e 
sua representação luminosa na aparência do fenômeno. O procedimento de Fichte não está calcado na pura negação do real através de abstrações sem limite; trata-se, pelo contrário, de uma decidida afirmação da realidade vivente, que tem na existência incondicional e necessária do saber, isto é, na realidade simultaneamente fática e genética de nosso conhecimento sua imagem reveladora.

Muito antes da dialética entre essência e aparência elaborada por Hegel na sua Ciência da Lógica Fichte desenvolve progressivamente nas versões tardias ${ }^{1}$ da $W L$ uma dialética epistêmica sobre o modo como nossas pressuposições ontológicas manifestam-se dentro do agir cognitivo, tentando com isto mostrar que a própria atitude realista-ontológica está fundamentada, em última instância, no idealismo superior que o percurso de muitas duplicidades superadas desvela ${ }^{2}$. Além disso, a lógica transcendental fichtiana, muitas vezes considerada simples malabarismo solipsista, é na verdade uma das primeiras e mais rigorosas tentativas de demonstrar como a filosofia - e conseqüentemente o pensar em geral - pode compreender a partir de seus próprios limites aquilo que designamos por absoluto.

O caminho da argumentação, contudo, difere radicalmente da sistemática hegeliana. Enquanto Hegel assume, seguindo a influência de Schelling, a posição neutra do desenvolvimento intrínseco da idéia mesma, tornando-se assim arauto de um processo autônomo, defensor de uma lógica cuja validade objetiva já está pressuposta de algum modo, Fichte elabora uma intrincada rede de relações recíprocas dentro da forma do pensar, partindo do simples raciocínio hipotético realizado pela vontade teórica do sujeito até culminar na afirmação incondicional da existência do saber, que projeta a si mesmo enquanto imagem do absoluto incognoscível e coincide com nossa própria existência. Isto não significa uma adequatio da representação ao representado, uma correspondência assimétrica e nesse sentido exterior entre manifestação finita e sua fonte absoluta ou divina. $\mathrm{O}$ idealismo fichtiano tem o intuito de encontrar na interioridade do saber - na dupla reflexividade do conhecimento humano, que sabe sobre si enquanto objeto e a partir de si enquanto existência - a lei que justifica sua realidade ontológica absoluta.

\footnotetext{
1 Sem dúvida a primeira inflexão do saber absoluto aparece já nitidamente desde a versão de 1801-02.

${ }^{2}$ Assim, a WL 1804 de Fichte aproxima-se muito mais da Fenomenologia do Espírito de Hegel, dividindo com esta "a tarefa de, através da crítica sistemática de toda posição unilateral do absoluto que permaneça no interior da "cisão" da consciência entre saber e ser, penetrar no saber verdadeiro do absoluto." (Siep, 1970, p. 50). (Esta e todas outras citações têm minha tradução).
} 
Com isso justifica-se também a eterna confluência entre ser e pensar como queria Hegel, mas o que este último considerou premissa inquestionável deve agora, de acordo com Fichte, ser deduzido geneticamente através de nossa visão e não somente a partir do que é visto. Como diz Wolfgang Janke: "o saber absoluto não é nem o ser absoluto mesmo, nem um nulificado não-ser, mas sim o ser na forma da visibilidade” (Janke, 1970, p. XIII). A Wissenschaftslehre de 1804, objeto do presente estudo, almeja cumprir esta difícil tarefa: direcionar nossa visão intelectiva para o próprio processo de ver e descobrir nesta auto-visão a essência mesma da imagem absoluta. Dito de outro modo, Fichte pretende realizar uma ambiciosa prova ontológica ${ }^{3}$ da existência do saber absoluto enquanto auto-intuição pura da própria luz, isto é, do nosso ver cognitivo.

\section{Com o que deve ser feito o começo da Doutrina-da-Ciência?}

Talvez a exposição mais clara e sucinta do problema que subjaz todo desenvolvimento da WL 1804 encontra-se na seguinte passagem do texto de Fichte: "isto foi precisamente a dificuldade de toda filosofia que não quis se tornar um dualismo, mas que levou a sério a busca pela unidade: que ou nós é que devemos perecer, ou Deus. Nós não o queremos, Deus não o pode!” (1985, p. 114-115). ${ }^{4}$ Estamos diante do verdadeiro fantasma que assola qualquer tentativa de estabelecer uma unidade sistemática dentro da própria filosofia, unidade esta referente não mais à superação da cisão entre sujeito e objeto finitos - o que estaria ainda restrito ao escopo da crítica kantiana mas sobretudo relativa ao que Kant denominou 'ideal da razão pura', isto é, a uma possível síntese entre a finitude do entendimento humano e sua almejada superação na infinitude de uma completude divina. A questão em jogo, portanto, consiste em decifrar o caminho de passagem entre estas duas realidades à primeira vista incomensuráveis entre si. Fichte deve demonstrar como podemos ascender progressivamente desde a finitude de nossas categorias fáticas de pensamento até à mais profunda gênese do próprio

\footnotetext{
${ }^{3}$ Cf. Fichte, 1985, pp. 400-1.

${ }^{4}$ Seguirei sempre a paginação indicada na edição crítica da Gesamtausgabe [GA] e não a versão editada e modificada por I.H. Fichte, a Sämmtliche Werke [SW]. Na edição crítica foram impressos lado a lado a versão do volume $X$ de SW e uma versão conhecida como Copia, encontrada na biblioteca de Halle, texto que possui diversas passagens esclarecedoras sobre possíveis problemas editorias da versão compilada pelo filho de Fichte.
} 
absoluto, sem recorrer a qualquer premissa dogmática que já pressuponha implicitamente a unidade a ser provada.

Assim, Fichte define já no início de sua primeira preleção o percurso a seguir, quando determina, ecoando motivos platônicos, o que considera ser a verdadeira essência da filosofia: "reconduzir toda multiplicidade (que se impõe a nós na visão da vida cotidiana) à absoluta unidade" (1985, p. 8). Qual seria então o ponto de partida adequado para dita recondução? Devemos, seguindo o exemplo de Hegel, começar pela determinação conceitual mais abstrata e, portanto, também mais pobre em conteúdo efetivo, a saber, o puro ser? Ou será que o início da $W L$ deve negar completamente o conceito de ser, representante mor do dogmatismo metafísico tão criticado por Fichte, e partir da consciência pura, iniciar pelo puro pensar?

Nem um, nem outro! Na verdade, a pergunta por si só está mal colocada. Não podemos tentar encontrar o que consta como ponto de partida na investigação fichtiana, pois isto já seria uma completa distorção da intenção presente no método da WL. Devemos, ao contrário, perguntar pelo como, pela atividade reflexiva que desempenhamos e que por sua vez constrói as primeiras hipóteses disponíveis. Como indica o próprio autor, fazendo uma implícita crítica a Schelling, “(...) o que importa não é como se nomeia este ser, senão como ele é interiormente captado e conservado. Pode muito bem ser chamado de eu. Se ele é originalmente objetificado e alienado de si, então torna-se justamente a velha coisa-em-si.” (1985, p. 10). Mesmo conceitos como consciência ou ipseidade podem cair na armadilha do modo de discurso metafísico, na constante fixação de "objetos" conceituais que "pairam" diante de um observador oculto.

$\mathrm{O}$ que aqui parece ser apenas um aspecto marginal do método filosófico não-ortodoxo de Fichte é, bem pelo contrário, imprescindível para a correta compreensão do projeto que o filósofo apresenta oralmente para seus alunos. Talvez aqui resida a maior inovação metódica da $W L$, inovação que antecipa em larga escala, e em certa medida ultrapassa em sua amplitude, a dimensão performática do discurso na teoria da pragmática transcendental. A investigação de Fichte pode ser descrita como um processo de análise racional que ao mesmo tempo é também um processo de auto-análise racional.

Além disso, cada etapa de um raciocínio, ou melhor, cada momento constituinte de uma investigação teórica acarreta sempre uma posição prática 
subjacente. Esta duplicidade retroativa de uma razão teórico-prática, elemento constante das "deduções" genéticas desenvolvidas na WL 1804, já está presente de forma incipiente na assim denominada Grundlage de 1794. A diferenciação que Fichte propõe entre $\mathrm{A}=\mathrm{A}$ e eu=eu é um bom exemplo disso: primeiramente, o autor parte de uma representação do princípio lógico de identidade formal, que afirma apenas uma proposição condicional $=\mathrm{X}$, ou seja, uma proposição hipotética, sem com isto postular a existência de um A qualquer, mas apenas a verdade da relação condicional pressuposta como necessária. ${ }^{5}$ Mas Fichte logo observa que a proposição eu=eu tem uma significação completamente diferente daquela outra identidade ${ }^{6}$. Da mesma forma que $\mathrm{X}$ (a hipótese condicional) é posto pelo eu como lei de sua consciência, também o eu=eu (formalmente equivalente a $\mathrm{X}$ ) está posto pelo próprio eu. A diferença está em que neste segundo pôr existe uma nova identidade entre forma e conteúdo da proposição, que se estabelece como identidade entre o eu que põe (e assim afirma a existência de $\mathrm{X}$ ) e o eu posto (como conteúdo da função $X(a) a=a$ ). No primeiro caso o $A=A$ permanece posto como uma mera forma lógica geral, não representando a instanciação do próprio eu que ao afirmar a hipótese afirma também com este ato uma tese incondicional.

Infelizmente a formulação desta teoria sui generis sobre uma possível lógica transcendental como fundamento de toda lógica predicativa perdeu-se na obscuridade da primeira apresentação publicada por Fichte, única versão integral da $W L$ que veio a público na época. Entretanto, Fichte não deixou de aperfeiçoar esta idéia e tal dialética entre os domínios pratico e teórico da razão desempenha papel crucial no curso de 1804, como veremos a seguir. Assim, é importante ressaltar que toda especulação filosófica desenvolvida pelo autor pressupõe um envolvimento reconstrutivo da parte do leitor, pois Fichte pretende realizar uma inédita síntese morfológica entre lógica racional e "lógica" existencial. Vejamos então, de maneira abreviada, como procede esta argumentação auto-reflexiva.

${ }^{5}$ Cf. Fichte, 1970, p. 93.

${ }^{6}$ Cf. Fichte, 1970, p. 95. 


\section{Do eu (ao) absoluto}

$\mathrm{Na}$ primeira lição da segunda série de preleções sobre a $W L$ de 1804 Fichte enumera claramente as pressuposições mais gerais que norteiam todo processo subseqüente de sua argumentação, as quais de certo modo definem a compreensão fichtiana do que significa a filosofia. São elas: 1) existe apenas uma verdade, una e imutável, que fundamenta toda multiplicidade do real; 2) logo, existe também apenas um único sistema filosófico possível, que retrata fielmente esta relação do uno e do múltiplo, tarefa primordial da filosofia; 3 ) este sistema só pode ser captado plenamente pela intuição individual imediata e, portanto, cada uma de suas etapas deve ser reconstruída na visão interior e vivente de cada um. "Sem esta livre e pessoal recriação da exposição da $W L$ na sua profundidade viva (...) não se obterá nenhum proveito destas lições.” (Fichte, 1985, p. 22).

De acordo com Fichte, a primeira pressuposição determina o que toda ambição filosófica pretende consciente ou inconscientemente encontrar. E a recusa de buscar dita unidade suprema ou sua transposição para uma unidade meramente fática reduz o conhecimento filosófico respectivamente a um ceticismo inócuo e improdutivo ou à simples história das idéias. Mas se todas as filosofias concordam em relação a sua finalidade última, discordam quase sempre com relação a seu princípio. Ora, se existe apenas uma verdade, só pode existir um único princípio verdadeiro, pois "princípios divergentes tornam-se resultados diferentes, com os quais surgem mundos inteiramente distintos e desconexos entre si;" (Fichte, 1985, p. 10). Conseqüentemente, de acordo com a segunda pressuposição supracitada, há somente uma filosofia sistemática. Até aqui Fichte simplesmente reafirma um projeto comum a todo idealismo alemão.

Mas através da terceira pressuposição, mesmo que indiretamente, Fichte pretende afirmar sua diferença com relação a toda tradição filosófica pré-kantiana, e inclusive com relação a Kant. Se existe um princípio fundamental, ele jamais poderá surgir fixado como axioma objetivo diante de um observador nulo ou indiferente. Entretanto, postular uma intuição imediata e individual do princípio não significa, como critica Hegel mais de uma vez, iniciar o saber absoluto com um tiro de pistola ${ }^{7}$, isto é, pressupor

${ }^{7}$ Cf. Hegel, G.W.F. Werke. Frankfurt a.M.: Suhrkamp, 1979; Phänomenologie des Geistes, v. 3, p. 31; Wissenschaft der Logik, v. 5, p. 65. 
uma capacidade especial e incomunicável de apreensão direta do próprio absoluto. O conhecimento intuitivo imediato ao qual Fichte se refere deve ser entendido ao mesmo tempo como sendo a capacidade criadora da faculdade da imaginação, que nos permite construir dinamicamente um conhecimento regido por leis a priori (por exemplo, na compreensão imediata de que somente uma reta pode ligar dois pontos no espaço euclidiano), bem como a propriedade reflexiva da consciência de ver a si mesma como presente e atuante neste processo construtivo e, assim, também auto-construtivo do saber. Nesse sentido, a intuição do puro saber e do saber de si como sendo este puro saber é o que caracteriza o método fichtiano de uma investigação ou "dedução" genética.

Além destes esclarecimentos metódicos necessários Fichte rapidamente antecipa o objetivo final ao qual deveremos chegar, a premissa que deverá ser provada através de todo percurso argumentativo da primeira metade do curso de 1804:

Portanto, a unidade absoluta não pode mais residir no ser nem na sua consciência correspondente; não pode ser posta nem na coisa nem na representação da coisa. Ao invés, ela reside no princípio, que acabamos de descobrir, da absoluta unidade e indivisibilidade de ambos, que é igualmente, como vimos, o princípio de sua disjunção. Nomearemos este princípio puro saber, saber em si mesmo, e, portanto, saber completamente sem objeto, pois de outro modo não seria um saber em si mas requereria objetividade para o seu ser. (1985, p. 14).

Vemos aqui por que Fichte não aceita que sua $W L$ seja reduzida a um simples idealismo subjetivo que postula somente a consciência ou pensamento puro como sendo o absoluto. $O$ final da passagem supracitada pode dar a entender justamente o contrário, pois ali é afirmada a necessidade de um saber sem objeto, um saber em-si tão dogmático e unilateral quanto o saber fundado na própria coisa ou no objeto-em-si. Mas o verdadeiro sentido desta afirmação de Fichte reside na sua concepção de saber puro. A relação sujeito-objeto deve ser vista como interna ao processo cognitivo enquanto tal, isto é, o sujeito conhecedor presencia na sua cognição objetal uma instância concreta da lei geral que rege sua constituição cognitiva. Logo adiante, 
veremos no que consiste esta unidade subjacente à duplicidade interna do saber. Por hora, quero apenas ressaltar que Fichte jamais defendeu a posição de um idealismo ingênuo, qual seja, aquele que pretende isolar radicalmente a subjetividade de qualquer relação com um objeto. Se há de fato uma primazia do sujeito em todo o processo, isto não se dá no nível fático de nosso saber objetal discursivo e deve ser buscado portanto em outra esfera do agir cognitivo.

De fato, Fichte reformula na sua obra tardia o papel que a consciência desempenha dentro do sistema do saber. Agora a consciência não é mais vista como fim último de toda reflexão transcendental, mas serve apenas como modelo ou imagem da auto-projeção que o saber puro efetua. A bem dizer, esta transformação do conceito de consciência (e mesmo do conceito de autoconsciência) traz consigo profundas dificuldades para a argumentação fichtiana. Podemos, por exemplo, nos perguntar ate que ponto Fichte se mantém fiel ao intuito original da virada transcendental da filosofia, ao tentar defender coerentemente tanto o desenvolvimento do saber absoluto interno à consciência quanto a separação radical entre a imagem do saber absoluto projetada na consciência e o saber absoluto em-si inacessível para esta mesma consciência. Pois Fichte diz que se a $W L$ "deve também admitir um absolutamente inconcebível, então ao menos ela o conceberá como sendo apenas o que ele é, i.e., como absolutamente inconcebível e nada mais; e portanto conceberá assim talvez a partir de onde deveria iniciar o conceber absoluto.” (1985, p. 32).

A partir da definição desta meta, que pretende reconstruir o absoluto através de sua negação, a WL começa uma análise das diversas bifurcações ou dualidades que o aparecer do absoluto apresenta faticamente na consciência. Parte-se da possibilidade mais consagrada na história do pensamento: da divisão do absoluto (A) em ser (S) e pensar (P). Fichte mostra que para cada elemento determinado por $S$ este sempre é acompanhado por um $\mathrm{P}$ respectivo. Ser e pensar são dois aspectos indissociáveis de qualquer aparecer finito no mundo. Mas se observarmos bem podemos encontrar ainda um fator superior que unifica este conjunto de pares ordenados. Em uma série de apreensões ' $\mathrm{S}_{1}-\mathrm{P}_{1}, \mathrm{~S}_{2}-\mathrm{P}_{2}, \mathrm{~S}_{3}-\mathrm{P}_{3},(. .$.$) ' temos sempre a mesma forma$ de apreensão, o mesmo saber para todos os diferentes casos específicos. $\mathrm{O}$ saber torna-se o ponto invariável que possibilita toda variação, pois como diz Fichte (1985, p. 38): 
Nesta parte do experimento, $S$ fez o P diferente em cada momento, pois o $P$ não era nada mais do que o $P$ para aquele $\mathrm{S}$ e desapareceu com ele. $\mathrm{Na}$ medida em que agora nos elevamos à segunda parte perguntando: não é o saber um e o mesmo do início ao fim? - e assim o encontrando, elevamonos sobre todas as diferenças de $\mathrm{P}$ bem como de $S(. .$.$) .$

Esta primeira disjunção aparente acaba por sua vez criando uma disjunção de segundo nível. Fichte agora observa, seguindo a idéia de que toda objetivação conceitual está sempre sustentada por uma síntese no próprio sujeito, tanto a invariância como a variação constituindo membros de uma nova dualidade. Entretanto, esta nova disjunção não representa, como antes havíamos notado, uma relação de equilíbrio entre os termos. A unidade entre variância e invariância ou mutabilidade e imutabilidade cria uma assimetria e revela, na verdade, uma assimetria necessária. Como se deve compreender tal assimetria? Assim responde Fichte (1985, p. 42): "sem dúvida que um dos dois [termos] seria captado mediatamente; e que este termo captado mediatamente de modo algum deveria ser a imutabilidade, que enquanto absoluto só pode se realizar absolutamente, mas a mutabilidade." Aqui pela primeira vez o percurso de desenvolvimento das figuras da consciência (as quais assumem na teoria de Fichte, ao contrário da fenomenologia hegeliana, um sentido estritamente epistemológico ${ }^{8}$ ) revela um elemento fundamental de sua constituição. A imutabilidade, enquanto fator absoluto do saber, é o que só pode ser captado imediatamente. A mutabilidade, ao contrário, é o que determina o caráter finito do saber enquanto mediação discursiva. Devemos entender a prioridade da imutabilidade como afirmação da primazia da unidade frente a qualquer diversidade possível. A assimetria da relação antes mencionada expressa uma lei necessária da consciência, qual seja, a exigência de completude do saber na sua totalidade sistêmica. "Este insight, que é completamente certo em si

\footnotetext{
${ }^{8}$ Sem dúvida, a expressão 'epistemológico' tem para Fichte um significado bem distinto de qualquer acepção contemporânea do termo, pois Fichte não pretende restringir a investigação transcendental a uma mera enumeração fática de leis lógicas da razão pura, como ele muitas vezes acusa Kant de ter feito. Também não se trata de uma análise das propriedades formais de nosso pensar, e sim de uma consideração simultânea destas formas da razão em sua relação com as ações e aspirações do espírito humano; a lógica transcendental fichtiana não é uma psicologia da lógica, mas uma teoria do conhecimento do fenômeno espiritual.
} 
mesmo, ocorreu a Kant como resultado da lei absoluta mas inconscientemente ${ }^{9}$ operativa da razão: que esta vem a termo apenas com a absoluta unidade, reconhece apenas isto como o absolutamente substancial e deriva todo mutável disto.” (Fichte, 1985, p. 44).

Voltamos, portanto, à pressuposição inicial de que o absoluto deve se mostrar como plena unidade na constituição do próprio saber. De acordo com a teoria fichtiana, esta conclusão provisória pode ser reformulada nos seguintes termos: "a mais alta evidência fática foi hoje apresentada por nós: o insight sobre a absoluta auto-suficiência do saber, sem nenhuma determinação por algo fora de si ou por algo mutável.” (Fichte, 1985, p. 44). Este postulado fundamental, que afirma de modo fático a necessária unicidade e absoluta autonomia do saber, deve também ser provado geneticamente. ${ }^{10} \mathrm{~A} W L$ precisa demonstrar como o absoluto constitui a si mesmo, mas isto só pode tornar-se evidente na própria forma como fazemos tal demonstração.

Tentarei fazer uma breve apresentação dos pontos principais que direcionam esta íngreme ascensão do saber fático até sua gênese absoluta no viver. Primeiramente, o argumento de Fichte retoma a distinção entre essência e aparência, colocando como termos negativamente relacionados por um lado a reconstrução do absoluto efetuada pela forma conceitual da consciência e, à parte disso, a validade intrínseca do inconcebível enquanto realização interna de uma gênese. ${ }^{11}$ As obscuras palavras abstratas de Fichte ocultam uma idéia simples: todo procedimento de representação, seguindo a lei interna da própria consciência, traduz a intuição pura da unidade em pares de relações recíprocas, isto é, a apreensão pelo conceito distorce a unidade fundamental do saber puro, criando nossas categorias habituais de compreensão (tempo/espaço; sensível/inteligível; essência/aparência). Como diz Fichte (1985, p. 78), “o princípio da divisão é o mesmo que o princípio da construção e, portanto, também do conceito.”

Mas é justamente através desta tomada de consciência sobre a disjunção anterior, disjunção que se estabelece entre o conjunto das disjunções da reconstrução e a unidade pressuposta como sua base, que surge um novo termo de síntese, uma unificação na alternância dos dois lados da

\footnotetext{
9 Termo da edição SW. Em GA aparece 'mecanicamente'.

${ }^{10}$ Cf. Fichte, 1985, p. 48.

${ }^{11}$ Cf. Fichte, 1985, p. 54.
} 
relação, ponto constante mas oculto que Fichte muitas vezes identifica com o próprio inconcebível. O autor, porém, faz a seguinte ressalva (1985, p. 58):

O absoluto não é intrinsecamente inconcebível, pois isto não faz sentido; ele é inconcebível apenas quando o conceito por si tenta alcançá-lo, e esta inconceptibilidade é sua única qualidade. Tendo reconhecido esta inconceptibilidade como uma qualidade estranha introduzida pelo saber, como eu disse antes, permanece no absoluto apenas a pura auto-suficiência, ou a substancialidade.

$\mathrm{Na}$ verdade, toda argumentação fichtiana assume esta forma geral: busca-se uma síntese entre dois termos aparentemente inconciliáveis entre si, pois um sempre aparece como fundamento incognoscível de sua aparência correspondente. Essência e manifestação emergem na própria reconstrução do puro saber. Mas na medida em que ambos emergem para a consciência, mesmo que relacionados negativamente, este aparecer de ambos postula por sua vez um terceiro termo requerido para a síntese da disjunção que aparece.

Nesse sentido, podemos entender melhor por que Fichte utiliza os conceitos de luz e imagem para explicar como se dá o saber enquanto fenômeno. A luz está sempre vinculada ao aparecer, é por assim dizer uma condição de possibilidade desse último. Qualquer afirmação ou negação, portanto, determina-se porque se torna visível à intuição ou, mediatamente, à intelecção pelo conceito. A luz permanece presente em todo ato consciente, mesmo que com isto muitas vezes não mantenha sua forma pura, ocultada pelas disjunções do pensar conceitual. "Considerar a luz nas suas qualidades internas, e o que disso segue, ao que prosseguiremos após este passo, é inteiramente diferente desse entregar-se e desaparecer na luz vivente. Aquela consideração como tal objetificará internamente e matará a luz.” (1985, p. 96). A luz absoluta, fonte vivente de todo aparecer, se resguarda encoberta pela luminosidade aparente do saber fático da consciência.

Outra explicação para a natureza fenomênica do saber surge com o conceito de imagem, que será melhor desenvolvido posteriormente nos cursos sobre lógica transcendental de 1812-14. De acordo com a própria acepção do termo, uma imagem só retém sentido na medida em que é imagem de um imaginado. Fichte antecipa aqui uma idéia central à teoria da intencionalidade de Husserl, quando mostra que toda representação 
consciente, em sendo imagem, aponta sempre para fora de si; da mesma forma, todo conteúdo imaginado só vem a ser através de sua imagem representada. Esta relação recíproca que constitui o sentido do termo 'imagem' revela o ponto culminante de qualquer síntese possível no âmbito do conceito, ponto que Fichte designa pelo neologismo Durcheinander. A alternância entre termos de uma relação recíproca reconstrói, em 1804, o que Fichte já propunha em sua Grundlage de 1794 ao retomar a teoria kantiana do esquematismo para descrever o papel da imaginação na síntese das oposições categoriais do entendimento.

Mas o que na parte teórica da primeira versão da $W L$ só se resolvia precariamente no regresso ao infinito da vontade prática é agora extirpado, como diz freqüentemente Fichte, com um único golpe. A síntese suprema requerida constantemente em cada etapa do processo dialético ascendente só consegue superar o regresso ao infinito na medida em que o próprio processo de busca revela-se como objeto visado. Toda duplicidade criada pela representação racional da totalidade é sempre um duplo postular de uma única vitalidade que se constrói como multiplicidade determinada. "Dito de modo simples, a unidade não pode de forma alguma consistir no que vemos ou concebemos como WL, pois isto seria algo objetivo; ao contrário, ela consiste naquilo que somos, buscamos e vivemos." (Fichte, 1985, p. 86). Fichte pretende desatar o nó que amarra aquele inexplicável absolutum hiatum entre ser e conceito, luz e imagem, eu e absoluto, descrevendo cada disjunção possível do pensar e mostrando internamente como tal apresentação fática do que aparece permanece em contínua insuficiência perante nosso agir transcendental criador. $O$ ponto final deste desdobramento das figuras da consciência, tal como em Hegel, também culmina na própria vida consciente, cuja identificação com o ser visado se torna visão de si. O caminho circular do espírito traz, em seu retorno, a lógica novamente para dentro da ética, e desse modo leva o sistema do saber à plenitude.

Mas, ao contrário de Hegel, esta clausura circular do saber jamais pode tomar o lugar do próprio espírito absoluto, pois a $W L$ é sempre um meio provisório para se atingir fins que a ultrapassam. A filosofia nunca pode ser a mais completa manifestação e auto-compreensão do espírito. Nesse sentido, Fichte e Wittgenstein concordam: "aquele que chegou lá não se importa mais com a escada.” (Fichte, 1985, p. 378). 
Fica aqui da mesma forma claro quão longe chega a dedução e reconstrução do saber verdadeiro na WL: a intuição pode intuir a si mesma, o conceito pode conceber a si próprio; tão longe um alcança, tanto o outro. O conceito encontra seu limite; concebe a si mesmo como limitado, e sua completa auto-concepção é o conceber de seu limites. O limite, o qual ninguém ultrapassará, mesmo sem qualquer requisição ou exigência nossa, ele reconhece exatamente; e para além dele encontra-se o uno, a pura luz vivente; (Fichte, 1985, p. 124). 


\section{Referências Bibliográficas}

FICHTE, J.G. Wissenschaftslehre 1804. Wahrheit- und Vernunftlehre I.XV. Vortrag. Frankfurt am Main: Vittorio Klostermann, 1966.

.Sämmtliche Werke. Berlin: Walter de Gruyter, 1970.

- Gesamtausgabe der Bayerischen Akademie der Wissenschaften, II, v. 8. Stuttgart: Frommann-Holzboog, 1985.

. Die Wissenschaftslehre. Zweiter Vortrag im Jahre 1804. Hamburg: Felix Meiner, 1986.

IVALDO, M. I Principi del Sapere. La visione trascendentale di Fichte. Napoli: Bibliopolis, 1987.

JANKE, W. Fichte. Sein und Reflexion. Grundlagen der kritischen Vernunft. Berlin: Walter de Gruyter, 1970.

SIEP, L. Hegels Fichtekritik und die Wissenschaftslehre von 1804. Freiburg: Karl Alber, 1970.

E-mail: thsan@redemeta.com.br

Recebido: junho/2007 Aprovado: dezembro/2007 